\title{
Antiparanodal antibodies and IgG subclasses in acute autoimmune neuropathy
}

Luise Appeltshauser, MD, Anna-Michelle Brunder, Annika Heinius, Peter Körtvélyessy, MD, Klaus-Peter Wandinger, MD, Ralf Junker, MD, Carmen Villmann, PhD, Claudia Sommer, MD, Frank Leypoldt, MD, and Kathrin Doppler, MD

Neurol Neuroimmunol Neuroinflamm 2020;7:e817. doi:10.1212/NXI.0000000000000817

\section{Abstract}

\section{Objective}

To determine whether IgG subclasses of antiparanodal autoantibodies are related to disease course and treatment response in acute- to subacute-onset neuropathies, we retrospectively screened 161 baseline serum/CSF samples and 66 follow-up serum/CSF samples.

\section{Methods}

We used ELISA and immunofluorescence assays to detect antiparanodal IgG and their subclasses and titers in serum/CSF of patients with Guillain-Barré syndrome (GBS), recurrent GBS (R-GBS), Miller-Fisher syndrome, and acute- to subacute-onset chronic inflammatory demyelinating polyradiculoneuropathy (A-CIDP). We evaluated clinical data retrospectively.

\section{Results}

We detected antiparanodal autoantibodies with a prevalence of $4.3 \%(7 / 161)$, more often in A-CIDP $(4 / 23,17.4 \%)$ compared with GBS (3/114, 2.6\%). Longitudinal subclass analysis in the patients with GBS revealed IgG2/3 autoantibodies against Caspr-1 and against anticontactin-1/Caspr-1, which disappeared at remission. At disease onset, patients with A-CIDP had IgG2/3 anti-Caspr-1 and anti-contactin-1/Caspr-1 or IgG4 anti-contactin- 1 antibodies, IgG3 being associated with good response to IV immunoglobulins (IVIg). In the chronic phase of disease, IgG subclass of one patient with A-CIDP switched from IgG3 to IgG4.

\section{Conclusion}

Our data (1) confirm and extend previous observations that antiparanodal IgG2/3 but not IgG4 antibodies can occur in acute-onset neuropathies manifesting as monophasic GBS, (2) suggest association of IgG3 to a favorable response to IVIg, and (3) lend support to the hypothesis that in some patients, an IgG subclass switch from IgG3 to IgG4 may be the correlate of a secondary progressive or relapsing course following a GBS-like onset.

\author{
Correspondence \\ Dr. Appeltshauser \\ Appeltshau_L@ukw.de
}

\section{RELATED ARTICLE}

\section{Editorial}

Isotyping paranodal antibodies in inflammatory neuropathies: One step closer to precision care

Page e843

\footnotetext{
From the Department of Neurology (L.A., A.-M.B., C.S., K.D.), University Hospital of Würzburg; Neuroimmunology Section (A.H., K.-P.W., R.J., F.L.), Institute of Clinical Chemistry, University Hospital of Schleswig-Holstein Campus Kiel; Department of Neurology (P.K.), University Hospital of Magdeburg; and Institute for Clinical Neurobiology (C.V.), University Hospital of Würzburg, Germany. 


\section{Glossary}

A-CIDP = acute-onset chronic inflammatory demyelinating polyradiculoneuropathy; Caspr-1 = contactin-1-associated protein-1; $\mathbf{C B A}=$ cell-based assay; $\mathbf{C I D P}=$ chronic inflammatory demyelinating polyradiculoneuropathy; $\mathbf{G B S}=$ Guillain-Barré syndrome; HEK = human embryonic kidney; HLA = human leukocyte antigen; ICU = intensive care unit; IVIg = IV immunoglobulin; MFS = Miller-Fisher syndrome; NF = neurofascin; OD = optical density; R-GBS = recurrent GBS.

Autoantibodies against the paranodal antigens contactin-1, contactin-associated protein-1 (Caspr-1), and neurofascin-155 (NF155) have been described as biomarkers for a new entity of inflammatory neuropathies classified as paranodopathies. ${ }^{1-3}$ In the chronic phase of disease, IgG4-seropositive patients do not respond to IV immunoglobulins (IVIg), but to rituximab. ${ }^{4-7}$ Noninflammatory IgG4 autoantibodies are pathogenic, possibly by inhibition of the interaction between contactin-1/Caspr-1 and NF155 and by NF155 depletion. ${ }^{8-11}$ Autoantibodies of the IgG3 subclass have been described (1) in monophasic disease, (2) at the subacute onset, (3) in patients with anti-panneurofascin autoantibodies and severe course of disease, and (4) most recently in chronic inflammatory demyelinating polyradiculoneuropathy (CIDP) with clinical features indistinguishable from seronegative patients but with a good response to IVIg. ${ }^{6,711-13}$ Proinflammatory IgG3 antibodies lead to complement deposition in vitro ${ }^{14}$ and in vivo, resulting in reversible conduction failure in Lewis rats intraneurally injected with anti-contactin- $1 \mathrm{IgG} 3^{15}$ and may therefore play a role in the acute onset of paranodopathies. However, data on antiparanodal autoantibodies in Guillain-Barré syndrome (GBS) or the acute onset of CIDP are scarce because previous studies mostly focused on CIDP and patients were recruited during the chronic phase of disease. IgG subclass distribution and the associated clinical phenotype have never been investigated longitudinally. We therefore aimed at determining the prevalence and IgG subclass of paranodal autoantibodies in a cohort of patients with acute to subacute inflammatory neuropathies including followup of seropositive patients. We hypothesize that IgG subclass and titer are related to the course of disease and therapeutic response in acute-onset paranodopathy.

\section{Methods}

\section{Patients and controls}

One hundred sixty-one patients with suspected GBS and subacute inflammatory neuropathy (peak of symptoms $\leq 90$ days) who had undergone diagnostic lumbar puncture at the University Hospitals of Kiel and Magdeburg between 2001 and 2016 were included into the study. We assessed clinical data retrospectively by analysis of discharge letters and documented laboratory, electrophysiologic, and MRI examinations. Table e-1, links.lww.com/NXI/A274, summarizes demographic data. The diagnosis of GBS was confirmed in $\mathrm{n}=114$ patients with diagnostic certainty according to the Brighton criteria ${ }^{16,17}$ : level 1 in 73 patients, level 2 in 29 patients, level 3 in 6 patients, and level 4 in 6 patients. We classified 6 patients as recurrent GBS (R-GBS) according to the criteria adapted from Kuitwaard et al. ${ }^{18}$ and 18 patients as Miller-Fisher syndrome (MFS). In 23 patients, the initial diagnosis was GBS, but was later reverted to CIDP because of a disease progression $>2$ months (diagnostic certainty according to the EFNS criteria ${ }^{19}$ : definite CIDP in 10 patients, probable CIDP in 3 patients, possible CIDP in 1 patient, and EFNS electrodiagnostic criteria not fulfilled in $9 / 23$ patients). Eighteen of 23 patients with CIDP fulfilled the criteria for acute-onset CIDP (A-CIDP) proposed in previous publications, ${ }^{20-22}$ and $5 / 23$ patients with CIDP showed a subacute-onset (peak $\leq 90$ days). In the following, all patients with acute- to subacute-onset CIDP are referred to as part of the A-CIDP cohort. Follow-up sera and CSF samples were available in 66 patients, including 3 seropositive patients. We included sera of 40 healthy controls recruited in former studies. ${ }^{6}$ Sera of all patients had already been tested for anti-NF155 autoantibodies in a previous study. ${ }^{12}$

\section{Binding assays on murine teased fibers}

We used binding assays on murine teased fibers at a serum dilution of 1:100 and 1:500 to screen all patients' and controls' sera for antiparanodal autoantibodies as previously described. ${ }^{23}$ Titers of seropositive samples were measured with a dilution series using $\mathrm{Cy} 3^{\mathrm{TM}}$-conjugated goat anti-human IgG 1:300 (Jackson, West Grove). In positive sera, we performed double immunofluorescence with sera diluted 1:50 and 1:100 and rabbit antiCaspr-1 diluted 1:1,000 (Abcam, Cambridge, United Kingdom), using MFP488-conjugated goat anti-human IgG diluted 1:500 (MoBiTec, Göttingen, Germany) and $\mathrm{Cy}^{\mathrm{TM}}{ }^{\mathrm{T}}$-conjugated donkey anti-rabbit IgG diluted 1:300 (Jackson) as secondary antibodies. For subclass analysis, we used FITC-conjugated secondary antibodies diluted 1:100, namely mouse anti-human IgG1, IgG4 (Abcam), mouse anti-human IgG2 (Merck, Darmstadt, Germany), and sheep anti-human IgG3 (Rockland Immunochemicals, Inc., Pottstown, PA). A healthy control serum and serum of patients with anti-Caspr-1 IgG3 and IgG4 antibodies from a previous study ${ }^{7}$ stained on separate slides served as negative and positive controls for double immunofluorescence and subclass analysis. We tested CSF of seropositive patients of the first assessment and follow-up on teased fibers in a dilution of 1:20 and 1:50 as described above. CSF of five patients who were seronegative served as negative controls.

\section{ELISA}

We performed ELISA for detection of anti-contactin-1 in duplets with sera of all patients and 40 healthy controls as previously described. ${ }^{6,12,23,24}$ For anti-Caspr-1 ELISA, we coated Chinese hamster ovary cell line-derived recombinant human Caspr-1 protein (Research and Diagnostic Systems, Inc., Minneapolis, $\mathrm{MN}$ ) at a dilution of $2 \mu \mathrm{g} / \mathrm{mL}$ on MaxiSorb 96-well 
plates (Thermo Scientific Fisher, Minneapolis, MN) and tested baseline/follow-up sera of seropositive patients and 40 healthy controls or rabbit anti-Caspr-1 (Lifespan Biosciences, Seattle, WA) in duplets, using corresponding horseradish peroxidaseconjugated secondary antibodies ${ }^{6}$ and conjugated anti-rabbit IgG (DakoCytomation, Glostrup, Denmark). For each sample, we subtracted corresponding values of uncoated duplet wells to reduce background signals. We set the threshold for both assays at 5 SDs above the mean of healthy controls. Antibody titers were determined by serial dilutions. Subclass-specific secondary antibodies served for subclass analysis as previously described. ${ }^{12}$ We tested CSF of seropositive patients in a dilution of 1:20 in anti-contactin-1 ELISA and anti-Caspr-1 ELISA (exception: patient 4 baseline CSF in both ELISAs and patient 3 in antiCaspr-1 ELISA due to lack of material) as described above, with CSF of 5 seronegative patients as negative controls.

\section{Preabsorption experiments}

To determine the specific paranodal target of the autoantibodies, we serially preincubated seropositive sera and serum from a healthy control with contactin-1 (CNTN1)- and Caspr-1 (CNTNAP1)-transfected human embryonic kidney (HEK) 293 cells as previously described ${ }^{7}$ and afterward performed binding assays on murine teased fibers as described above.

\section{Cell-based assay}

For specification, we tested sera of patients positive in teased fibers assay or ELISA and sera of five controls on HEK293 cells transfected with plasmids of human Caspr-1 (CNTNAP1) and rat contactin-1 (CNTN1) as previously described ${ }^{7,23}$ and used polyclonal rabbit anti-contactin-1 IgG (Abcam) and monoclonal mouse anti-Caspr-1 IgG1 (Santa Cruz Biotechnology, Dallas, TX) for double immunofluorescence in positive patients with corresponding $\mathrm{Cy} 3^{\mathrm{TM}}$-conjugated donkey anti-rabbit IgG (Abcam), donkey anti-mouse IgG, and MFP488-conjugated goat anti-human IgG (MoBiTec) secondary antibodies. Sera of patients with anti-Caspr-1 and anti-contactin-1 antibodies from previous studies ${ }^{6,7}$ served as positive controls and sera of healthy controls as negative controls in the double immunofluorescence assays.

\section{Statistical analysis}

We performed statistical analysis (descriptive statistics, calculation of OR, and 95\% CI) with SPSS 25.0 (IBM, Armonk, NY).

\section{Standard protocol approvals, registrations, and patient consents}

The Ethics Committees of the University of Würzburg and the University of Kiel approved to conduct this study. Written informed consent was obtained from all participants in the study.

\section{Data availability}

Data not published within this article are available at the University Hospital of Würzburg or will be shared in an anonymized manner on request from any qualified investigator for purposes of replicating procedures and results.

\section{Results}

\section{Antiparanodal autoantibodies of different IgG subclasses in $4.3 \%$ of the patients}

We applied immunofluorescence binding assays on murine teased fibers as a screening tool for detection of antiparanodal autoantibodies. We observed serum binding to the paranodal junctional region colocalizing with the commercial anti-Caspr-1 antibody (figure 1A) in seven patients of the total cohort (7/161; prevalence $4.3 \%)$, in none of the patients of the R-GBS $(0 / 6)$ and MFS $(0 / 18)$ subcohort, nor in the healthy controls $(0 / 40)$, but in $3 / 114(2.6 \%)$ of the GBS subcohort and 4/23 (17,4\%) of the A-CIDP subcohort. Thus, paranodal autoantibodies occurred more frequently in A-CIDP compared with GBS (OR $=7.79$, 95\% CI 1.61-37.95). Two of the sera with paranodal binding (1 GBS and 1 A-CIDP) had been identified as anti-NF155 seropositive in a recent study ${ }^{12}$; therefore, experimental findings and clinical associations of these patients are not reported here. Target antigens of the other five seropositive patients were determined using cell-based assay (CBA; figure 1B) and ELISA (see below) and confirmed by preabsorption experiments (figure 1C). In the GBS subcohort, the two seropositive patients showed anti-Caspr-1 (patient 1) and anti-contactin-1/Caspr-1 (patient 2) antibodies. Seropositive A-CIDP patients carried antibodies against either contactin-1 (patient 3), contactin-1/Caspr-1 (patient 4) or antiCaspr-1 (patient 5). At the onset of disease, the two patients with GBS showed IgG2 and IgG3 antibodies (table 1). During the acute phase at onset, sera of the three patients later classified as A-CIDP carried IgG2/4 (patient 3) and IgG2/3 (patients 4 and 5), as detected by binding assays and ELISA (figure 2, A and B). Autoantibody titers are shown in table 1 . The results of the binding assays on teased fibers, ELISA, and CBA showed concordance regarding the specific target antigen of the antibodies and the predominating IgG subclass. There were only minor differences of the antibody titer and coexisting subclasses in ELISA and teased fibers assay. In case of double positivity for anti-contactin-1/ Caspr-1 (patients 2 and 4), preabsorption assays detected only the dominating antibody (table 1).

\section{Subclass switch from IgG3 to IgG4 at follow-up in one patient}

In 66/161 patients, follow-up serum and CSF samples were available, including three seropositive patients (1 GBS and 2 A-CIDP). None of the follow-up sera of initially seronegative patients or controls showed positive results in the teased fibers assay (data not shown) nor in the contactin-1 ELISA (figure 3A). Serum of the patient with GBS acquired in remission 55 months after the first assessment, when the patient did not show any remaining neurologic deficits, was seronegative in all experimental assays (figure 3, B and C). 


$\begin{array}{cccccc}\text { A } & \text { Negative } & \text { Patient 1 } & \text { Patient 2 } & \text { Patient 3 } & \text { Patient 4 } \\ \text { control } & \text { (GBS) } & \text { (GBS) } & \text { (A-CIDP) } & \text { (A-CIDP) } & \text { Patient 5 } \\ & \text { (A-CIDP) }\end{array}$

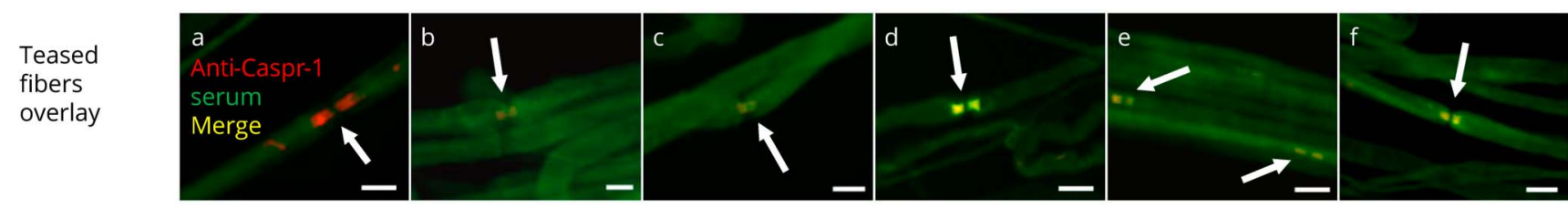

B

contactin-1

transfected
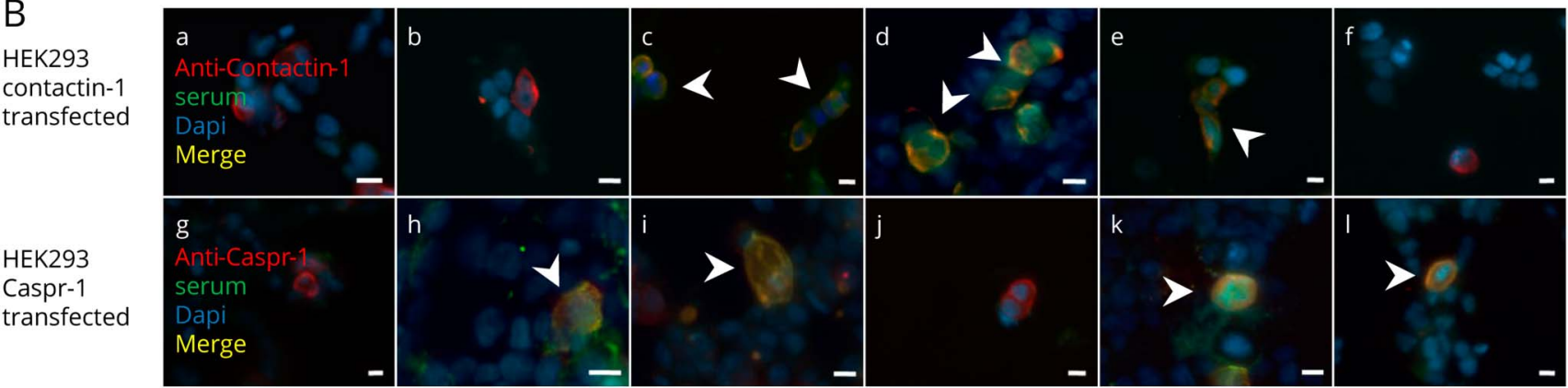

C

Negative control

Patient 3 (A-CIDP)

Teased

fibers

HEK293-

preabsorbed
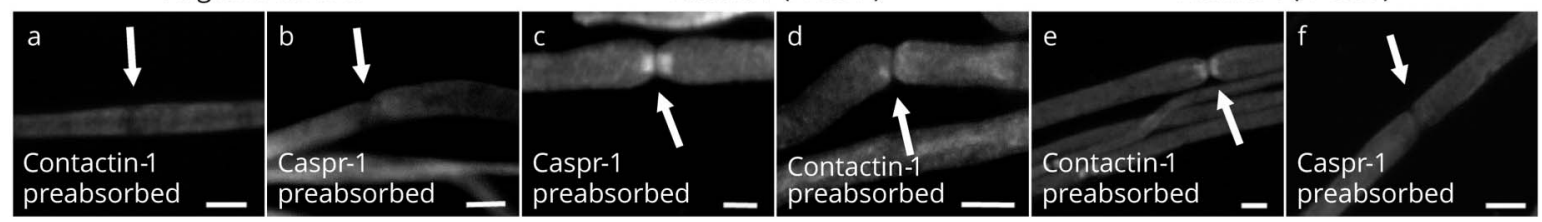

(A) Colocalization overlay photomicrographs of double immunofluorescence assays with commercial autoantibody displayed in red and human serum in green. Colocalization at the paranodes (arrows) appears yellow and indicates antiparanodal autoantibodies in patients 1-5 (A.b-A.f), but not in the negative control serum (A.a). (B) The specific target of the autoantibodies is illustrated by colocalization overlay photomicrographs on transfected HEK293 cells (arrowheads) with commercial antibody in red, serum in green, and nucleus staining in blue. Colocalization appears yellow (merge) and confirms anticontactin-1 in patients 2 (B.C), 3 (B.d), and 4 (B.e), but not in patients 1 (B.b), 5 (B.f), and the negative control (B.a). Sera of patients 1, 2, 4 , and 5 (B.h, B.i, B.k, and B.I) colocalize on Caspr-1 (CNTNAP1)-transfected HEK293 cells as proof of anti-Caspr-1 autoantibodies, whereas sera of the negative control (B. $g$ ) and patient 3 (B.j) do not show anti-Caspr-1 positivity. (C) Single immunofluorescence on murine teased fibers after HEK293 contactin-1 and Caspr-1 preabsorption shows that antiparanodal autoantibodies disappear after contactin-1 preabsorption in patient 3 (C.d) and after Caspr-1 preabsorption in patient 4 (C.f), proving specificity to the respective target antigen. Scale bar $=10 \mu \mathrm{m}$. CBA = cell-based assay; HEK = human embryonic kidney.

Follow-up serum of one patient with A-CIDP two months after onset, i.e., still in the acute phase of disease (patient 5), showed IgG3 autoantibodies against Caspr-1, with no difference in antibody titer and subclass compared with onset (figure 3, B and C). A follow-up-sample during the chronic stage (28 months after the onset) revealed a reduction of the titer (1:50 in teased fibers, negative in ELISA, table 1$)$ of anti-Caspr-1 IgG autoantibodies with subclasses not measurable due to the low titer (data not shown). The patient now presented with only very mild sensorimotor impairment and ameliorated nerve conduction studies. Follow-up serum and CSF of the other patient with A-CIDP (patient 4) who was initially IgG3-anti-contactin-1/Caspr-1 double positive were acquired 120 months after the acute onset, when the patient had developed relapsing-remitting sensorimotor CIDP. At follow-up, we could no longer detect anti-contactin-1, but detected and confirmed anti-Caspr-1 autoantibodies via anti-Caspr-1 ELISA, CBA, and preabsorption assay (table 1 and figure $3, \mathrm{~B}$ and $\mathrm{C}$ ). Subclass analysis now revealed reactivity against IgG2/4, but not IgG3 subclass anymore, giving evidence of a switch of IgG subclasses between the acute and chronic stage of the disease (figure 2C).

\section{Intrathecal antiparanodal autoantibodies in patients with high antibody titer and blood- brain barrier dysfunction}

ELISA with CSF samples of the seropositive patients and five disease controls showed elevated optical density (OD) at a dilution of 1:20 only in anti-contactin-1 patient 3 with a very high serum titer (see appendix e-1, links.lww.com/ NXI/A275) and anti-Caspr-1 patient 5 with signs of severely disrupted blood-brain barrier (high CSF protein, MRI cauda equina enhancement, see appendix e-1, links.lww. com/NXI/A275), but equally low OD values for the other seronegative and seropositive patients (see figure e-1, links. lww.com/NXI/A273). Binding assays on murine teased fibers showed weak binding of CSF to the paranodes in these two patients, but not in the other seropositive patients or controls. None of the seropositive patients showed signs of intrathecal autoantibody production, with CSF IgG index and antiparanodal autoantibody specific ASI (antibody 
Table 1 Summary of the autoantibody status of seropositive patients 1-5 at baseline and follow-up

\begin{tabular}{|c|c|c|c|c|c|c|}
\hline & \multirow[t]{3}{*}{ CSF } & \multicolumn{5}{|c|}{ Serum } \\
\hline & & \multicolumn{3}{|c|}{ Teased fibers and ELISA } & \multirow[t]{2}{*}{ Preabsorption } & \multirow[t]{2}{*}{ CBA } \\
\hline & & & Titer & IgG subclass & & \\
\hline \multicolumn{7}{|c|}{ Patient 1 (baseline, no follow-up) } \\
\hline Teased fibers & Negative & Positive & 1:100 & IgG3 & & \\
\hline Contactin-1 & 0.202 & 0.465 & n.d. & n.d. & Negative & Negative \\
\hline Caspr-1 & 0.072 & 2.961 & $1: 200$ & n.m. & Positive & Positive \\
\hline \multicolumn{7}{|c|}{ Patient 2 (baseline) } \\
\hline Teased fibers & Negative & Positive & $1: 200$ & n.d. & & \\
\hline Contactin-1 & 0.247 & 3.538 & $1: 200$ & IgG2 & Negative & Positive \\
\hline Caspr-1 & 0.129 & 3.965 & $1: 1,000$ & IgG2 & Positive & Positive \\
\hline \multicolumn{7}{|c|}{ Patient 2 (follow-up) } \\
\hline Teased fibers & n.d. & Negative & n.d. & n.d. & & \\
\hline Contactin-1 & n.d. & 0.039 & n.d. & n.d. & n.d. & Negative \\
\hline Caspr-1 & n.d. & 0.025 & n.d. & n.d. & n.d. & Negative \\
\hline \multicolumn{7}{|c|}{ Patient 3 (baseline, no follow-up) } \\
\hline Teased fibers & Negative & Positive & $1: 30,000$ & IgG4 & & \\
\hline Contactin-1 & 0.516 & 4.492 & $1: 40,000$ & $\operatorname{lgG} / 2$ & Positive & Positive \\
\hline Caspr-1 & n.d. & 0.073 & n.d. & n.d. & Negative & Negative \\
\hline \multicolumn{7}{|c|}{ Patient 4 (baseline) } \\
\hline Teased fibers & Negative & Positive & $1: 500$ & IgG3 & & \\
\hline Contactin-1 & 0.267 & 2.294 & $1: 200$ & IgG3 & Negative & Positive \\
\hline Caspr-1 & n.d.* & 3.011 & $1: 500$ & $\operatorname{lgG} 3 / 2$ & Positive & Positive \\
\hline \multicolumn{7}{|c|}{ Patient 4 (follow-up) } \\
\hline Teased fibers & Negative & Positive & 1:500 & IgG4 & & \\
\hline Contactin-1 & 0.227 & 0.206 & n.d. & n.d. & Negative & Negative \\
\hline Caspr-1 & 0.138 & 3.618 & $1: 500$ & IgG2/4 & Positive & Positive \\
\hline
\end{tabular}


Table 1 Summary of the autoantibody status of seropositive patients 1-5 at baseline and follow-up (continued)

CSF

Serum

\begin{tabular}{|c|c|c|c|c|c|c|}
\hline & \multirow[t]{2}{*}{ CSF } & \multicolumn{5}{|c|}{ Serum } \\
\hline & & \multicolumn{3}{|c|}{ Teased fibers and ELISA } & \multirow[t]{2}{*}{ Preabsorption } & \multirow[t]{2}{*}{ CBA } \\
\hline & \multicolumn{2}{|c|}{ Paranodal binding/OD } & Titer & IgG subclass & & \\
\hline \multicolumn{7}{|c|}{ Patient 5 (baseline) } \\
\hline Teased fibers & Positive & Positive & 1:100 & IgG3 & & \\
\hline Contactin-1 & 0.219 & 0.260 & n.d. & n.d. & Negative & Negative \\
\hline Caspr-1 & 0.136 & n.d.* & n.d.* & n.d.* & Positive & Positive \\
\hline \multicolumn{7}{|c|}{ Patient 5 (first follow-up) } \\
\hline Teased fibers & Positive & Positive & 1:100 & IgG3 & & \\
\hline Contactin-1 & 0.236 & 0.243 & n.d. & n.d. & Negative & Negative \\
\hline Caspr-1 & 0.364 & 3.802 & 1:200 & $\lg G 3 / 2$ & Positive & Positive \\
\hline \multicolumn{7}{|c|}{ Patient 5 (second follow-up) } \\
\hline Teased fibers & n.d. & Positive & $1: 50$ & n.m. & & \\
\hline Contactin-1 & n.d. & 0.168 & n.d. & n.d. & n.d. & Negative \\
\hline Caspr-1 & n.d. & 0.013 & n.d. & n.d. & n.d. & Negative \\
\hline
\end{tabular}

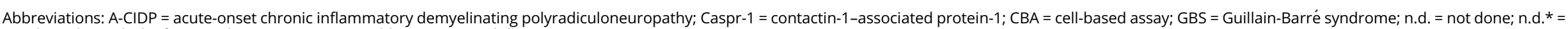
not done due to lack of material; n.m. = not measurable; OD = optical density.

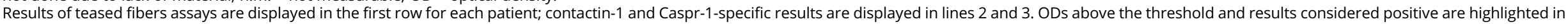

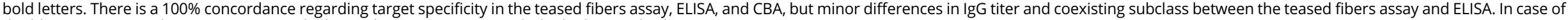
double positivity, preabsorption assays only detect the target antigen with the higher antibody titer (see ELISA titer). 
Figure 2 Serum subclass analysis at baseline and at follow-up with IgG subclass switch

A. Anti-contactin-1 subclasses

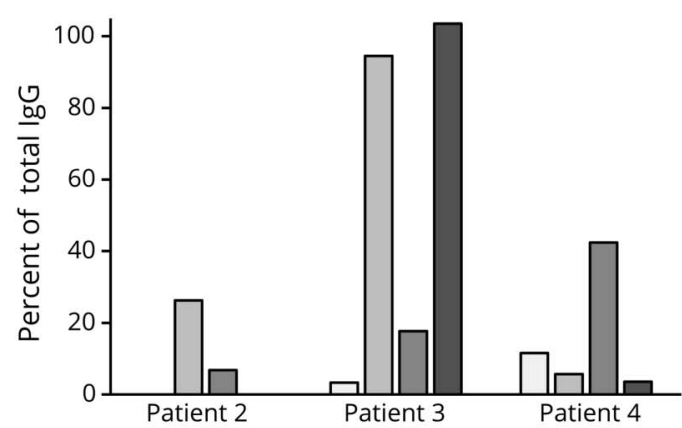

Anti-Caspr-1 subclasses

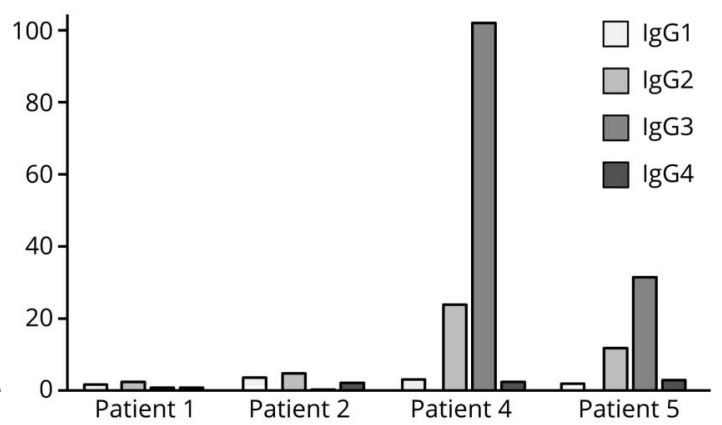

B. Acute phase teased fibers subclasses

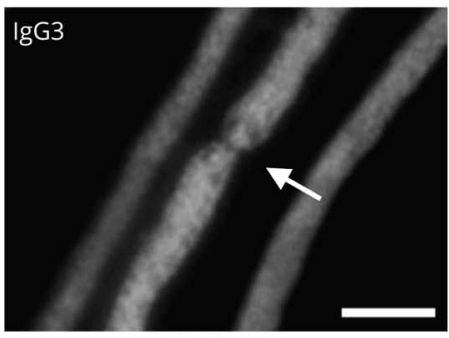

Patient 1

C. Anti-Caspr-1 subclasses

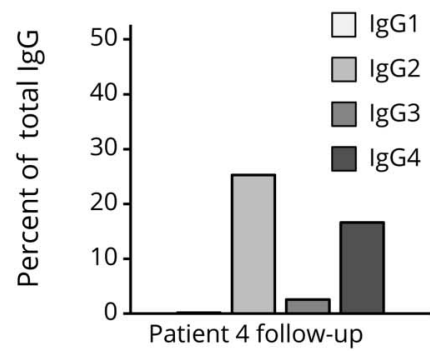

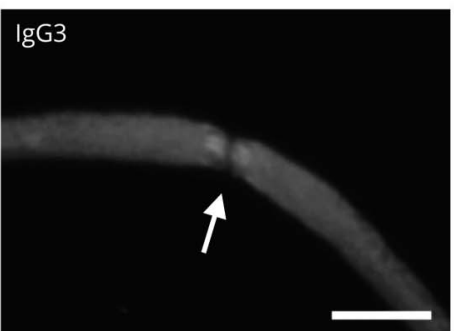

Patient 4

Chronic phase teased fibers subclasses

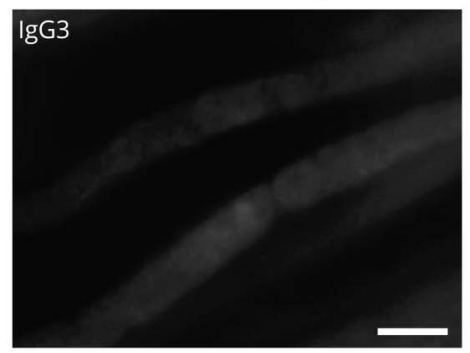

Patient 4 follow-up

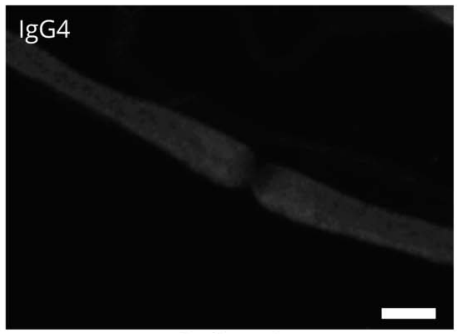

Patient 4

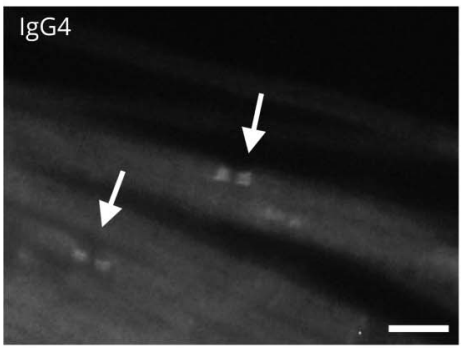

Patient 4 follow-up

(A) Results of anti-contactin-1 and anti-Caspr-1 ELISA with baseline sera and subclass-specific IgG1-4 autoantibodies (grayscale) are shown as \% of the OD of the total IgG (using anti-human IgG autoantibody) on y-axis. In patient 1, ELISA IgG subclasses were not measurable. ELISA revealed mainly IgG2 subclass in patient 2 (GBS), IgG2/IgG4 in patient 3 (A-CIDP), and IgG2/3 in patients 4 and 5 (A-CIDP). (B) Acute phase teased fibers subclass analysis with baseline sera showed binding to the paranodal regions (arrows) only when using IgG3-specific secondary antibody in patients 1 (GBS) and 4 (A-CIDP), visualized by photomicrographs of single immunofluorescence staining on teased fibers. (C) Anti-Caspr-1 IgG subclass ELISA with follow-up serum of patient 4 now revealed IgG 2/4 subclass. Photomicrographs show immunofluorescence staining of murine teased fibers with subclass-specific IgG3 and IgG4 autoantibodies at follow-up. Paranodal binding disappeared using IgG3 antibody, but occurred using IgG4 subclass-specific antibody, proving subclass switch in patient 4. Scale bar = $10 \mu \mathrm{m}$. A-CIDP = acute-onset chronic inflammatory demyelinating polyradiculoneuropathy; GBS = Guillain-Barré syndrome.

specificity index) being in a normal range (see appendix e-1, links.lww.com/NXI/A275).

\section{Clinical features of seropositive patients}

Figure 4 schematically summarizes the clinical course related to the experimental results. Appendix e-1, links.lww.com/ NXI/A275, summarizes clinical data of seropositive patients 1-5 and provides a detailed description of the clinical disease course in individuals. The two seropositive patients with GBS were both middle-aged women presenting with severe motor, but only mild sensory involvement. Cranial nerve involvement, autonomic symptoms, and neuropathic pain were present in $1 / 2$ patients with GBS only. Both patients required treatment on the intensive care unit (ICU). The three patients with A-CIDP presented with moderate to severe paresis and multimodal sensory impairment at disease onset. During the course of disease, all three patients with A-CIDP reported neuropathic pain requiring pregabalin/gabapentin or even opioid treatment. Two of three patients with A-CIDP presented sensory ataxia. Nerve conduction studies showed demyelinating features in all seropositive patients with conduction block in $3 / 5$ patients. Sural nerve biopsy was performed in one patient (patient 5) six months after the onset and showed axonal loss without signs of demyelination. CSF analysis revealed cytoalbuminologic dissociation and blood-brain barrier dysfunction in all seropositive patients. The patient with subacute-onset CIDP, highly elevated CSF protein, and detection of anti-Caspr-1 in both serum and 

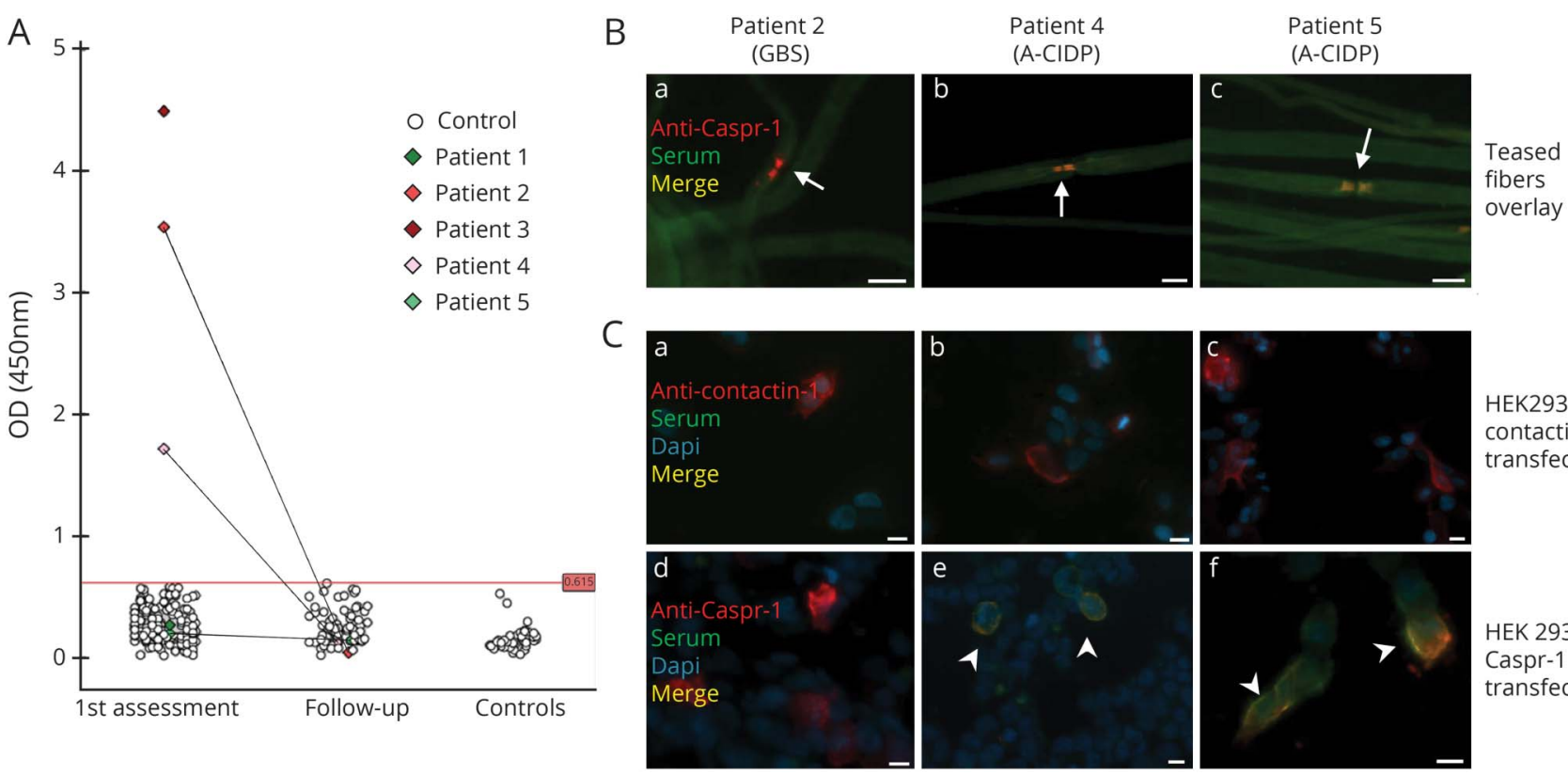

HEK293

contactin-1 transfected

(A) Contactin-1 IgG ELISA of all patients at first assessment, of 66/161 patients at follow-up, and of 40 healthy controls. Optical density (OD) at $450 \mathrm{~nm}$ is displayed on the $y$-axis. The threshold for positive results is set at 5 SDs above the mean of controls $(0.615)$. Patients $2-4$ show positive results at first assessment. The other patients and controls show values below the threshold. Sera of patients 2, 4, and 5 are negative in anti-contactin-1 IgG ELISA at followup, as well as 63 other follow-up sera. Patients 1 and 3 were lost to follow-up. (B) Overlay photomicrographs of teased fibers double immunofluorescence and (C) contactin-1- and Caspr-1 (CNTNAP1)-transfected HEK293 cells show loss of anti-contactin-1/Caspr-1 autoantibodies in patient 2 (GBS) at follow-up (B.a, C.a, C.d), but colocalization of commercial anti-Caspr-1 antibody and sera at paranodes in patients 4 and 5 with A-CIDP (B.b, B.C, arrows). Both sera bind to Caspr-1 (CNTNAP1)-transfected HEK293 cells (C.e, C.f, arrowheads), but not to contactin-1-transfected cells (C.b, C.c). Scale bar $=10 \mu \mathrm{m}$. A-CIDP $=$ acute-onset chronic inflammatory demyelinating polyradiculoneuropathy; GBS = Guillain-Barré syndrome; HEK = human embryonic kidney.

CSF (patient 5) developed action tremor during the course of disease.

\section{Antibody status is concordant with disease activity and therapy response}

One of two patients with GBS (patient 2) received IVIg, which did not lead to amelioration. This patient was IgG2 > IgG3 seropositive (patient 2, figure $2 \mathrm{~A}$ ). Both patients with GBS responded well to plasma exchange. The two patients with A-CIDP and IgG3 autoantibodies (patients 4 and 5) showed good response to IVIg treatment in the acute phase of disease. Ongoing IVIg treatment led to further improvement of symptoms and was stopped after 25 cycles in patient 5 because of a remission of symptoms. In the other patient with A-CIDP and anti-contactin-1/Caspr-1 IgG3 at disease onset (patient 4), IVIg showed a good therapeutic effect in the acute phase and led to remission not requiring further therapy. In the chronic phase, IVIg was initiated again and stopped after 26 cycles because of a loss of the therapeutic effect. At that stage, the autoantibody subclass had already switched from IgG3 to IgG4 (for detailed treatment response in the course of disease, see appendix e-1, links.lww.com/NXI/A275). The patient with A-CIDP and high-titer anti-contactin-1 IgG4 autoantibodies (patient 3 ) had to be treated on ICU because of the severity of symptoms, developed renal dysfunction, did not respond to IVIg treatment, and did not ameliorate during the course of disease.

\section{Discussion}

We detected antiparanodal autoantibodies in $4.3 \%$ of patients with acute to subacute immune-mediated neuropathy, more frequently in CIDP with acute to subacute onset than in GBS. We found $\operatorname{IgG2} / 3$ in monophasic GBS, which supports the notion of previous studies that IgG3 is the predominant subclass in monophasic disease. ${ }^{7}$ By analyzing sera from different time points, we could show that the antibody status was concordant with the disease severity. Therefore, our data support pathogenicity of autoantibodies and suggest that autoantibody status and titer are valid indicators for disease activity, as proposed in previous studies on paranodopathy and further IgG4-related neurologic diseases. ${ }^{25-27}$

In one patient, we could demonstrate a subclass switch from IgG3 in acute disease to IgG4 in chronic disease, a finding that we had hypothesized in a previous study. ${ }^{6}$ In other autoimmune diseases, e.g., in membranous glomerulonephritis, subclass switch of anti-PLA2R autoantibodies from IgG1 to IgG4 also associates with progression to chronic disease. ${ }^{28}$ According to a linear model of autoantibody response, unspecific IgM response is followed by IgG isotype, produced by antigen-experienced B cells. These IgG are of the IgG3 subclass and sequentially switch to IgG1, 2 and $4 .^{29,30}$ Concurrently, autoantibodies strongly gain antigen affinity, with IgG4 showing the highest affinity to its target. ${ }^{31,32}$ Disease progression in paranodopathy might therefore depend on IgG subclass properties 


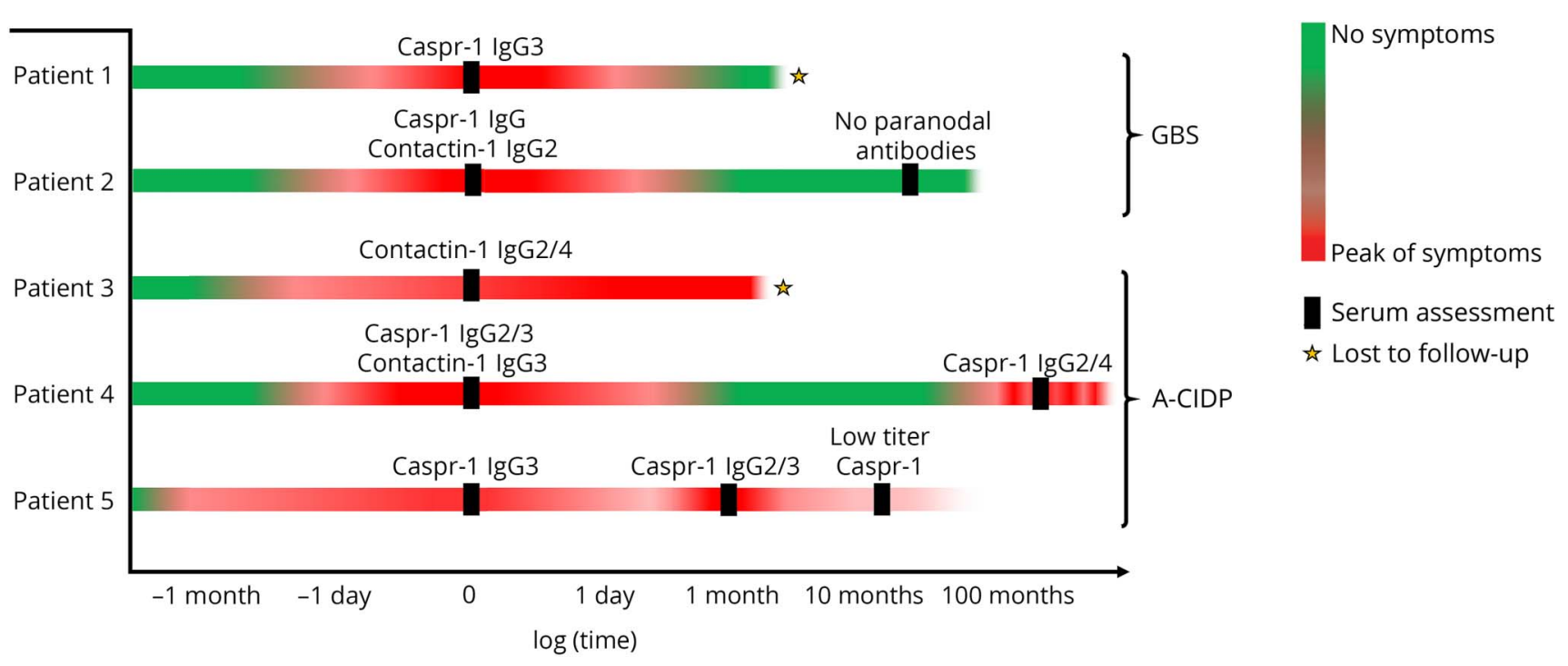

The course of disease is shown on the $\mathrm{x}$-axis by pseudo-logarithmic display of the time course. Time point 0 is set at baseline assessment of serum/CSF. The color code indicates severity of symptoms. Results of serum assessment are displayed in black. Patients 1 and 3 were lost to follow-up.

and affinities. Gain of specificity and affinity at switch from IgG3 to IgG4 might explain different binding characteristics of antiparanodal autoantibodies in the patient whose IgG3 autoantibodies reacted both against contactin-1/Caspr-1 epitopes, but whose IgG4 autoantibodies were specific to Caspr-1. Here, we report IgG2/4 (1) in patient 4 in the chronic phase after subclass switch and (2) in another patient at disease onset, showing nonameliorating disease with high disability similar to previous reports on anti-contactin-1 IgG4-related disease. ${ }^{11,13,33}$ So far, studies have only reported antiparanodal IgG4 autoantibodies in patients with chronic disease. ${ }^{7,11,34,35}$ We therefore suggest that high-affinity IgG4 autoantibody binding leads to chronic disease, with functional impairment possibly caused by disturbance of the antigen interaction, paranodal architecture, and paranodal complex formation as demonstrated previously. ${ }^{6,8-11}$

Patients of our study with predominant IgG3 subclass showed good response to IVIg, whereas patients with IgG2 and IgG4 initially did not respond to IVIg or lost responsiveness in the disease course. Several studies described good responses to IVIg in IgG3-associated paranodopathy, but poor responses in IgG4-associated disease. ${ }^{5,6,11,13,34}$ IgG3 can initiate complement activation, opsonization, antigen cross-linking, and internalization, whereas IgG2 shows little C1q binding and IgG4 completely lacks these $\mathrm{Fc}$-mediated effector functions. ${ }^{31}$ In an in vivo study on anti-contactin-1 pathogenicity, we suggested complement-mediated functional impairment at the paranodes as the pathophysiologic correlate in IgG3-mediated paranodopathy earlier and could show in vitro that IVIg inhibits complement deposition and activation dose-dependently. ${ }^{14,15}$ Our data therefore support the hypothesis that therapy responsiveness might depend on IgG subclass and subclassrelated pathomechanism of antiparanodal autoantibodies. If validated in larger studies, these findings might have a direct impact on the treatment regime in affected patients. Testing of autoantibody subclass during the course of disease may be useful as an indicator of a positive response to IVIg in case of IgG3, whereas IgG4-related paranodopathy shows very good response to rituximab. $4,6,7,11$

The trigger of the autoantibody production and the pathomechanism behind possible IgG switching are still unknown. Three of five seropositive patients in this study had diabetes mellitus type 2 as a comorbidity diagnosed years before the onset of disease. Previous studies report disruption of the bloodbrain barrier and the nodal architecture in patients with diabetes mellitus, thereby possibly exposing paranodal antigens to the immune response. ${ }^{36,37}$ A recent study has identified human leukocyte antigen (HLA)-DRB15 as a risk factor for CIDP associated with anti-NF155 antibodies, and another study reported different HLA antibody patterns with subclass switch after renal transplantation. ${ }^{38,39}$ Whether interindividual differences in antibody production and switching during the course of disease depend on (1) HLA alleles, (2) antigen exposure, or (3) further immunologic mechanisms has to be investigated in further studies.

Regarding characteristic clinical features of paranodopathy, we report neuropathic pain in anti-Caspr-1-related disease as previously described in patients with higher autoantibody titers. ${ }^{7}$ Different titers might explain discrepancies between our results and a recent study that did not report pain in anti-Caspr1-positive patients. ${ }^{7,11}$ In our patients, further features of IgG4related chronic paranodopathy such as tremor, sensory ataxia, and nephropathy $5,6,13,40$ were only present in the course of disease, suggesting that they evolve due to chronic autoantibody 
exposure. The pathomechanistic correlate of action tremor, which recently has also been described in anti-Caspr-1 IgG3related paranodopathy, ${ }^{11}$ is still under research, but studies suggest cerebellar origin. ${ }^{5,6,12}$ In this study, we detected intrathecal autoantibodies in a patient with tremor, as previously reported in a case of anti-pan-neurofascin-positive paranodopathy. ${ }^{12}$ The antiparanodal autoantibodies most probably diffuse into the intrathecal compartment due to a blood-brain barrier dysfunction, as indicated by normal IgG and ASI indices in our patients. Our CSF data suggest that detection of antiparanodal antibodies in CSF shows little sensitivity and depends on either high titer or strong leakage of the blood-brain barrier. We therefore encourage further studies on intrathecal antiparanodal autoantibodies targeting sensitivity, pathogenicity, and association to clinical symptoms.

Low prevalence of autoantibodies against paranodal proteins in acute inflammatory neuropathy, retrospective assessment, and the low number of seropositive patients available for follow-up limit our study. Clinical characteristics at acute onset and subclassrelated seropositivity as a possible risk factor for chronic progression when detected at the onset should be investigated in large multicentric studies, considering low overall prevalence of GBS and A-CIDP as well as further possible confounders in analysis of paranodopathy-specific clinical symptoms, e.g., coinciding painful diabetic neuropathy. The question of sequential subclass switching in paranodopathy needs to be addressed in larger prospective studies. Nevertheless, our data (1) propose autoantibody subclass screening to be considered in patients with GBS and A-CIDP, as results might have direct implications on diagnosis and therapeutic regime during the course of disease, and (2) pave the way for further clinical and pathomechanistic studies on antiparanodal autoantibodies in acute to subacute immune-mediated neuropathy.

\section{Acknowledgment}

The authors thank Barbara Reuter and Antonia Kohl for their superb technical assistance. They thank Maximilian Frömmer for provision and processing of clinical data and PD Dr. Jakob Matschke for provision of slides and images of supplementary morphologic data. The study was supported by a grant of the Interdisciplinary Center of Clinical Research of the Medical Faculty of Würzburg to $\mathrm{KD}$ and $\mathrm{CV}$ and a grant of the German Research Foundation to KD (DFG, DO-2219/1-1). LA is supported by a research fellowship as a clinician scientist of the Interdisciplinary Center of Clinical Research of the Medical Faculty of Würzburg. FL receives funding from the German Ministry of Education and Research (BMBF, 01GM1908A) and the German Research Foundation (DFG, LE3064/2-1). CS receives funding from the German Research Foundation (DFG 328/9-1; DFG UE 171/4-1; DFG SO 328/10-1; DFG, SFB 1158; and DFG SO 328 13/1), from the German Ministry of Education and Research (BMBF CMT-Net PI), and from the European Union (Horizon 2020).

\section{Study funding}

This study was supported by the Open Access Publication Fund of the University of Würzburg.

\section{Disclosure}

L. Appeltshauser, K-P. Wandinger, R. Junker, C. Sommer, F. Leypoldt, and $\mathrm{K}$. Doppler work for an academic institution offering commercial antibody diagnostics. A.M. Brunder, A. Heinius, P. Körtvelyéssy, and C. Villmann report no disclosures relevant to the manuscript. C. Sommer has served on scientific advisory boards for Algiax, Alnylam, Air Liquide, Akcea, Astellas, Bayer, Grifols, Takeda, and UCB. She reports being a member of speakers' bureau and receiving speaker honoraria from Akcea, Alnylam, Novartis, Pfizer, SanofiAventis, and Teva. C. Sommer served as a journal editor, associate editor, or editorial advisory board member for the European Journal of Neurology, PLoS ONE, and PAIN Reports. F. Leypoldt reports speaker honoraria from Bayer, Roche, Novartis, and Fresenius, travel funding from Merck, Grifols, and Bayer, and serving on advisory boards for Roche, Biogen, and Alexion. Go to Neurology.org/NN for full disclosures.

\section{Publication history}

Received by Neurology: Neuroimmunology \& Neuroinflammation March 2, 2020. Accepted in final form May 19, 2020.

Appendix Authors

\begin{tabular}{|c|c|c|}
\hline Name & Location & Contribution \\
\hline $\begin{array}{l}\text { Luise } \\
\text { Appeltshauser, } \\
\text { MD }\end{array}$ & $\begin{array}{l}\text { University Hospital of } \\
\text { Würzburg }\end{array}$ & $\begin{array}{l}\text { Major role in the acquisition, } \\
\text { analysis, and interpretation } \\
\text { of the data and drafting and } \\
\text { revising the manuscript for } \\
\text { intellectual content }\end{array}$ \\
\hline $\begin{array}{l}\text { Anna-Michelle } \\
\text { Brunder }\end{array}$ & $\begin{array}{l}\text { University Hospital of } \\
\text { Würzburg }\end{array}$ & $\begin{array}{l}\text { Major role in the acquisition } \\
\text { and analysis of the data }\end{array}$ \\
\hline Annika Heinius & $\begin{array}{l}\text { University Hospital of } \\
\text { Schleswig-Holstein, } \\
\text { Campus Kiel }\end{array}$ & $\begin{array}{l}\text { Major role in the acquisition } \\
\text { and analysis of the data }\end{array}$ \\
\hline $\begin{array}{l}\text { Peter } \\
\text { Körtvélyessy, } \\
\text { MD }\end{array}$ & $\begin{array}{l}\text { University Hospital of } \\
\text { Magdeburg }\end{array}$ & $\begin{array}{l}\text { Revising the manuscript for } \\
\text { intellectual content and } \\
\text { contribution of vital } \\
\text { reagents/tools/patients }\end{array}$ \\
\hline $\begin{array}{l}\text { Klaus-Peter } \\
\text { Wandinger, MD }\end{array}$ & $\begin{array}{l}\text { University Hospital of } \\
\text { Schleswig-Holstein, } \\
\text { Campus Kiel }\end{array}$ & $\begin{array}{l}\text { Revising the manuscript for } \\
\text { intellectual content and } \\
\text { contribution of vital } \\
\text { reagents/tools/patients }\end{array}$ \\
\hline Ralf Junker, MD & $\begin{array}{l}\text { University Hospital of } \\
\text { Schleswig-Holstein, } \\
\text { Campus Kiel }\end{array}$ & $\begin{array}{l}\text { Revising the manuscript for } \\
\text { intellectual content and } \\
\text { contribution of vital } \\
\text { reagents/tools/patients }\end{array}$ \\
\hline $\begin{array}{l}\text { Carmen } \\
\text { Villmann, PhD }\end{array}$ & $\begin{array}{l}\text { University Hospital of } \\
\text { Würzburg }\end{array}$ & $\begin{array}{l}\text { Revising the manuscript for } \\
\text { intellectual content and } \\
\text { contribution of vital } \\
\text { reagents/tools/patients }\end{array}$ \\
\hline $\begin{array}{l}\text { Claudia } \\
\text { Sommer, MD }\end{array}$ & $\begin{array}{l}\text { University Hospital of } \\
\text { Würzburg }\end{array}$ & $\begin{array}{l}\text { Conceptualization of the } \\
\text { study; revising the } \\
\text { manuscript for intellectual } \\
\text { content; and major role in } \\
\text { interpretation of data }\end{array}$ \\
\hline $\begin{array}{l}\text { Frank Leypoldt, } \\
\text { MD }\end{array}$ & $\begin{array}{l}\text { University Hospital of } \\
\text { Schleswig-Holstein, } \\
\text { Campus Kiel }\end{array}$ & $\begin{array}{l}\text { Drafting and revising the } \\
\text { manuscript for intellectual } \\
\text { content; design and } \\
\text { conceptualization of the } \\
\text { study; and major role in } \\
\text { interpretation of data }\end{array}$ \\
\hline
\end{tabular}


Appendix (continued)

\begin{tabular}{lll}
\hline Name & Location & Contribution \\
\hline $\begin{array}{ll}\text { Kathrin } \\
\text { Doppler, MD }\end{array}$ & $\begin{array}{l}\text { University Hospital of } \\
\text { Würzburg }\end{array}$ & $\begin{array}{l}\text { Drafting and revising the } \\
\text { manuscript for intellectual } \\
\text { content; design and } \\
\text { conceptualization of the } \\
\text { study; major role in analysis } \\
\text { and interpretation of data; } \\
\text { and study supervision }\end{array}$ \\
& \\
& \\
\hline
\end{tabular}

\section{References}

1. Fehmi J, Scherer SS, Willison HJ, Rinaldi S. Nodes, paranodes and neuropathies. J Neurol Neurosurg Psychiatry 2018;89:61-71.

2. Uncini A, Vallat JM. Autoimmune nodo-paranodopathies of peripheral nerve: the concept is gaining ground. J Neurol Neurosurg Psychiatry 2018;89:627-635.

3. Querol L, Illa I. Paranodal and other autoantibodies in chronic inflammatory neuropathies. Curr Opin Neurol 2015;28:474-479.

4. Querol L, Rojas-Garcia R, Diaz-Manera J, et al. Rituximab in treatment-resistan CIDP with antibodies against paranodal proteins. Neurol Neuroimmunol Neuroinflamm 2015;2:e149. doi: 10.1212/NXI.0000000000000149.

5. Querol L, Nogales-Gadea G, Rojas-Garcia R, et al. Neurofascin IgG4 antibodies in CIDP associate with disabling tremor and poor response to IVIg. Neurology 2014;82: 879-886.

6. Doppler K, Appeltshauser L, Wilhelmi K, et al. Destruction of paranodal architecture in inflammatory neuropathy with anti-contactin-1 autoantibodies. J Neurol Neurosurg Psychiatry 2015;86:720-728.

7. Doppler K, Appeltshauser L, Villmann C, et al. Auto-antibodies to contactinassociated protein 1 (Caspr) in two patients with painful inflammatory neuropathy. Brain 2016;139:2617-2630.

8. Manso C, Querol L, Mekaouche M, Illa I, Devaux JJ. Contactin-1 IgG4 antibodies cause paranode dismantling and conduction defects. Brain 2016;139:1700-1712.

9. Manso C, Querol L, Lleixa C, et al. Anti-Neurofascin-155 IgG4 antibodies prevent paranodal complex formation in vivo. J Clin Invest 2019;129:2222-2236.

10. Labasque M, Hivert B, Nogales-Gadea G, Querol L, Illa I, Faivre-Sarrailh C. Specific contactin $\mathrm{N}$-glycans are implicated in neurofascin binding and autoimmune targeting in peripheral neuropathies. J Biol Chem 2014;289:7907-7918.

11. Cortese A, Lombardi R, Briani C, et al. Antibodies to neurofascin, contactin-1, and contactin-associated protein 1 in CIDP: clinical relevance of IgG isotype. Neurol Neuroimmunol Neuroinflamm 2019;7:e639. doi: 10.1212/NXI.0000000000000639.

12. Stengel H, Vural A, Brunder AM, et al. Anti-pan-neurofascin IgG3 as a marker of fulminant autoimmune neuropathy. Neurol Neuroimmunol Neuroinflamm 2019;6: e603. doi: 10.1212/NXI.0000000000000603.

13. Miura Y, Devaux JJ, Fukami Y, et al. Contactin 1 IgG4 associates to chronic inflammatory demyelinating polyneuropathy with sensory ataxia. Brain 2015;138:1484-1491.

14. Appeltshauser L, Weishaupt A, Sommer C, Doppler K. Complement deposition induced by binding of anti-contactin-1 auto-antibodies is modified by immunoglobulins. Exp Neurol 2017;287:84-90.

15. Doppler K, Schuster Y, Appeltshauser L, et al. Anti-CNTN1 IgG3 induces acute conduction block and motor deficits in a passive transfer rat model. J Neuroinflammation 2019;16:73.

16. Sejvar JJ, Kohl KS, Gidudu J, et al. Guillain-Barre syndrome and Fisher syndrome: case definitions and guidelines for collection, analysis, and presentation of immunization safety data. Vaccine 2011;29:599-612.

17. Fokke C, van den Berg B, Drenthen J, Walgaard C, van Doorn PA, Jacobs BC. Diagnosis of Guillain-Barre syndrome and validation of Brighton criteria. Brain 2014; $137: 33-43$.
18. Kuitwaard K, van Koningsveld R, Ruts L, Jacobs BC, van Doorn PA. Recurrent Guillain-Barre syndrome. J Neurol Neurosurg Psychiatry 2009;80:56-59.

19. Van den Bergh PY, Hadden RD, Bouche P, et al. European Federation of Neurological Societies/Peripheral Nerve Society guideline on management of chronic inflammatory demyelinating polyradiculoneuropathy: report of a joint task force of the European Federation of Neurological Societies and the Peripheral Nerve Societyfirst revision. Eur J Neurol 2010;17:356-363.

20. Ruts L, Drenthen J, Jacobs BC, van Doorn PA. Distinguishing acute-onset CIDP from fluctuating Guillain-Barre syndrome: a prospective study. Neurology 2010;74: $1680-1686$.

21. McCombe PA, Pollard JD, McLeod JG. Chronic inflammatory demyelinating polyradiculoneuropathy. A clinical and electrophysiological study of 92 cases. Brain 1987; 110:1617-1630

22. Alessandro L, Pastor Rueda JM, Wilken M, et al. Differences between acute-onset chronic inflammatory demyelinating polyneuropathy and acute inflammatory demyelinating polyneuropathy in adult patients. J Peripher Nerv Syst 2018;23: 154-158

23. Doppler K, Appeltshauser L, Kramer HH, et al. Contactin-1 and neurofascin-155/186 are not targets of auto-antibodies in multifocal motor neuropathy. PLoS One 2015;10:e0134274.

24. $\mathrm{Ng} \mathrm{JK}$, Malotka J, Kawakami N, et al. Neurofascin as a target for autoantibodies in peripheral neuropathies. Neurology 2012;79:2241-2248.

25. Fujita A, Ogata H, Yamasaki R, Matsushita T, Kira JI. Parallel fluctuation of anti-neurofascin 155 antibody levels with clinico-electrophysiological findings in patients with chronic inflammatory demyelinating polyradiculoneuropathy. J Neurol Sci 2018;384:107-112.

26. Niks EH, van Leeuwen Y, Leite MI, et al. Clinical fluctuations in MuSK myasthenia gravis are related to antigen-specific IgG4 instead of IgG1. J Neuroimmunol 2008 195:151-156.

27. Huijbers MG, Vink AF, Niks EH, et al. Longitudinal epitope mapping in MuSK myasthenia gravis: implications for disease severity. J Neuroimmunol 2016;291 $82-88$

28. Huang CC, Lehman A, Albawardi A, et al. IgG subclass staining in renal biopsies with membranous glomerulonephritis indicates subclass switch during disease progression. Mod Pathol 2013;26:799-805.

29. Collins AM, Jackson KJ. A temporal model of human $\operatorname{IgE}$ and IgG antibody function Front Immunol 2013;4:235

30. Valenzuela NM, Schaub S. The Biology of IgG subclasses and their clinical relevance to transplantation. Transplantation 2018;102:S7-S13.

31. Vidarsson G, Dekkers G, Rispens T. IgG subclasses and allotypes: from structure to effector functions. Front Immunol 2014;5:520-532.

32. Bruhns P, Iannascoli B, England P, et al. Specificity and affinity of human Fcgamma receptors and their polymorphic variants for human IgG subclasses. Blood 2009;113:3716-3725.

33. Querol L, Nogales-Gadea G, Rojas-Garcia R, et al. Antibodies to contactin-1 in chronic inflammatory demyelinating polyneuropathy. Ann Neurol 2013;73:370-380.

34. Devaux JJ, Miura Y, Fukami Y, et al. Neurofascin-155 IgG4 in chronic inflammatory demyelinating polyneuropathy. Neurology 2016;86:800-807.

35. Ogata H, Yamasaki R, Hiwatashi A, et al. Characterization of IgG4 anti-neurofascin 155 antibody-positive polyneuropathy. Ann Clin Transl Neurol 2015;2:960-971.

36. Doppler K, Frank F, Koschker AC, Reiners K, Sommer C. Nodes of Ranvier in skin biopsies of patients with diabetes mellitus. J Peripher Nerv Syst 2017;22:182-190.

37. Banks W. The blood-brain barrier interface in diabetes mellitus: dysfunctions, mechanisms, and approaches to treatment. Curr Pharm Des 2020;26:1438-1447.

38. Arnold ML, Ntokou IS, Doxiadis II, Spriewald BM, Boletis JN, Iniotaki AG. Donorspecific HLA antibodies: evaluating the risk for graft loss in renal transplant recipients with isotype switch from complement fixing IgG1/IgG3 to noncomplement fixing IgG2/IgG4 anti-HLA alloantibodies. Transpl Int 2014;27:253-261.

39. Martinez-Martinez L, Lleixa MC, Boera-Carnicero G, et al. Anti-NF155 chronic inflammatory demyelinating polyradiculoneuropathy strongly associates to HLADRB15. J Neuroinflammation 2017;14:224.

40. Hashimoto Y, Ogata H, Yamasaki R, et al. Chronic inflammatory demyelinating polyneuropathy with concurrent membranous nephropathy: an anti-paranode and podocyte protein antibody study and literature survey. Front Neurol 2018;9:997. 


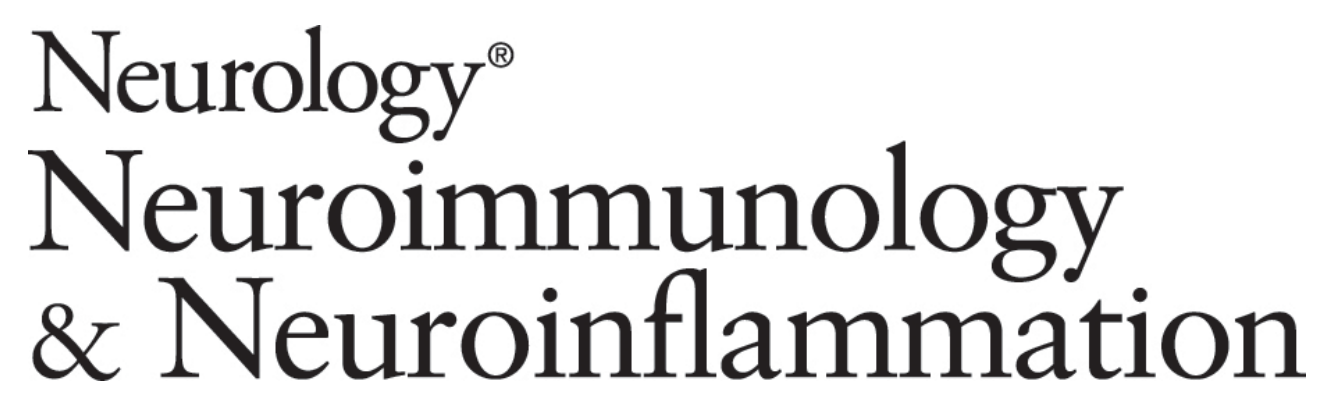

Antiparanodal antibodies and IgG subclasses in acute autoimmune neuropathy Luise Appeltshauser, Anna-Michelle Brunder, Annika Heinius, et al.

Neurol Neuroimmunol Neuroinflamm 2020;7;

DOI 10.1212/NXI.0000000000000817

This information is current as of July 24, 2020

Neurol Neuroimmunol Neuroinflamm is an official journal of the American Academy of Neurology.

Published since April 2014, it is an open-access, online-only, continuous publication journal. Copyright

Copyright $\odot 2020$ The Author(s). Published by Wolters Kluwer Health, Inc. on behalf of the American

Academy of Neurology.. All rights reserved. Online ISSN: 2332-7812.

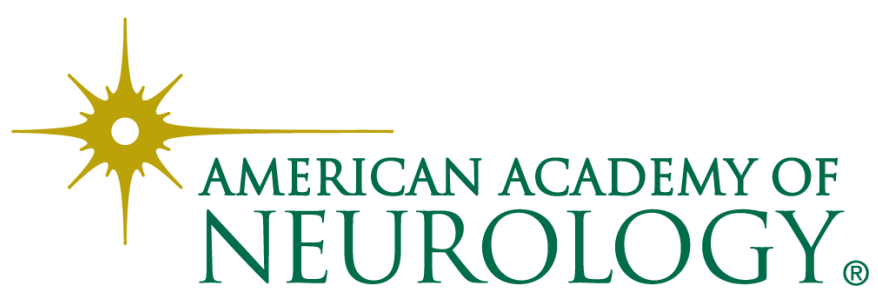




\section{Updated Information \& Services}

References

Citations

Subspecialty Collections

Permissions \& Licensing

Reprints including high resolution figures, can be found at: http://nn.neurology.org/content/7/5/e817.full.html

This article cites 40 articles, 9 of which you can access for free at: http://nn.neurology.org/content/7/5/e817.full.html\#\#ref-list-1

This article has been cited by 5 HighWire-hosted articles: http://nn.neurology.org/content/7/5/e817.full.html\#\#otherarticles

This article, along with others on similar topics, appears in the following collection(s):

\section{All Neuromuscular Disease}

http://nn.neurology.org//cgi/collection/all_neuromuscular_disease Autoimmune diseases

http://nn.neurology.org//cgi/collection/autoimmune_diseases

Chronic inflammatory demyelinating polyneuropathy

http://nn.neurology.org//cgi/collection/chronic_inflammatory_demyeli nating_polyneuropathy

Guillain-Barre syndrome

http://nn.neurology.org//cgi/collection/guillainbarre_syndrome

Peripheral neuropathy

http://nn.neurology.org//cgi/collection/peripheral_neuropathy

Information about reproducing this article in parts (figures,tables) or in its entirety can be found online at:

http://nn.neurology.org/misc/about.xhtml\#permissions

Information about ordering reprints can be found online:

http://nn.neurology.org/misc/addir.xhtml\#reprintsus

Neurol Neuroimmunol Neuroinflamm is an official journal of the American Academy of Neurology.

Published since April 2014, it is an open-access, online-only, continuous publication journal. Copyright

Copyright $\odot 2020$ The Author(s). Published by Wolters Kluwer Health, Inc. on behalf of the American

Academy of Neurology.. All rights reserved. Online ISSN: 2332-7812.

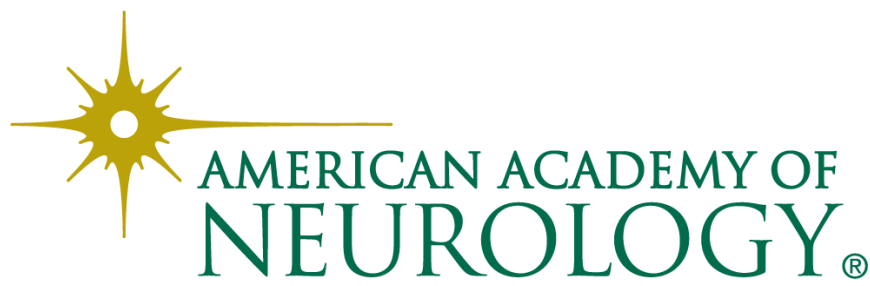

